\title{
Free ferulic acid uptake in lactating cows
}

\author{
M. A. Soberon, ${ }^{\star 1}$ J. H. Cherney,† R. H. Liu,‡ D. A. Ross, ${ }^{\star}$ and D. J. R. Cherney* \\ *Department of Animal Science, \\ †Department of Crop and Soil Sciences, and \\ fDepartment of Food Science, Cornell University, Ithaca, NY 14853
}

\section{ABSTRACT}

Ferulic acid (FRA), a phenolic compound with antioxidant and anticancer activities, naturally occurs in plants as a lignin precursor. Many veins of research have been devoted to releasing FRA from the lignin complex to improve digestibility of ruminant feeds. Thus, the objective of this research was to investigate the transfer of a given dosage of the free form of FRA into the milk of dairy cattle. Six mid- to late-lactation Holstein cows at the Cornell Research Farm (Harford, NY) were given 14-d adaptation to diet and stall position. Ad libitum access to a total mixed ration based on haylage and maize silage $(31.1 \%$ neutral detergent fiber containing $5.52 \mathrm{mg}$ of $\mathrm{FRA} / \mathrm{g}$ ) was provided during the study. A crossover design was implemented so that each cow alternated weekly between FRA-dosed and control. On d 1, jugular cannulas and urine catheters were placed in all cows. On d 2, FRA-dosed cows received a single dosage of $150 \mathrm{~g}$ of pure FRA powder at $0830 \mathrm{~h}$ via their fistula $(\mathrm{n}=4)$ or a balling gun for nonfistulated cows $(\mathrm{n}=2)$. Plasma, urine, feces, feed, orts, milk, and rumen fluid were sampled intensively for the next $36 \mathrm{~h}$ and analyzed for FRA concentration. On $\mathrm{d} 8$, the cows crossed over and the experiment was repeated. When compared with the control, FRA administration did not have an effect on dry matter intake, milk yield, milk fat yield, milk protein yield, somatic cell count, or neutral detergent fiber content of orts and feces. The concentration of FRA in the feces did not change as a result of FRA dosage. As expected, FRA concentration increased dramatically upon FRA dosage and decreased over time until returning to basal levels in rumen fluid ( $4 \mathrm{~h}$ after dosage), plasma (5.5 $\mathrm{h}$ after dosage), urine (10 $\mathrm{h}$ after dosage), and milk (14 h after dosage). Baseline values for FRA in urine and rumen fluid were variable among cows and had an effect on FRA concentration in FRA-dosed cows. From this study, it is observed that orally ingested FRA can be transported into the milk and that the physiological

Received October 4, 2011.

Accepted June 27, 2012.

${ }^{1}$ Corresponding author: mas329@cornell.edu transfer of FRA occurs from rumen to milk within 6.5 $\mathrm{h}$ or the first milking after dosage. Ferulic acid may affect the functionality of milk due to its antioxidant, anticancer, and antibacterial activities. Future research will be required to elucidate whether FRA in milk is bioavailable and bioactive, and to evaluate the complete sensory and microbiological effects of increased FRA and FRA degradation products in milk.

Key words: ferulic acid, milk, cow, phenolic

\section{INTRODUCTION}

Ferulic acid (FRA) is a phytochemical commonly found in fruits, vegetables, beverages, and cereals. It is also ubiquitous in forage species as a naturally occurring phenolic compound that functions as a chemical bridge between cell wall carbohydrates and lignin (Jung and Allen, 1995). Many veins of research have been focused on releasing FRA from the lignin complex to improve digestibility of ruminant feeds (Faulds et al., 2002; Yu et al., 2002; Mathew and Abraham, 2004) as well as to improve the bioavailability of FRA in human diets (Bourne and Rice-Evans, 1998; Adam et al., 2002). The release of increased free FRA in the diet could have a variety of implications for dairy cattle especially if the FRA is transferred into milk. However, due to the interest in FRA as a human dietary supplement, few studies have investigated the absorption of FRA in either lactating animals or ruminants.

In a preliminary study using ram lambs, oral doses of FRA were excreted primarily in the urine, supporting the idea that FRA was absorbed into the blood and could, therefore, be taken up by ruminant peripheral tissues such as the mammary gland (Soberon et al., 2012a). Increased FRA concentration in milk could be accomplished by using esterase treatments on cattle feed to release ferulates that could potentially enhance the health benefits of milk consumed. Because consumer perception of milk as a healthy source of nutrients is vital to the dairy industry, increased FRA concentration in milk could be desirable for multiple reasons. Regular ingestion of FRA may provide substantial protection against various oxidative stress-related diseases, including cancer, diabetes, and cardiovascular and 
neurodegenerative diseases, due to its potent antioxidant activity (Srinivasan et al., 2007). Moreover, the inhibition of oxidation due to natural antioxidants in milk could potentially reduce the autoxidation of milk lipids to prolong the stability and shelf life of milk (Ou and Kwok, 2004). Because the concentration of FRA in milk depends upon its absorption and tissue distribution, the objective of this study was to track the fate of a given dosage of FRA in the dairy cow to determine the likelihood of its transfer from ingested feed to milk when available in free form.

\section{MATERIALS AND METHODS}

\section{Selection of Subject Animals and Dosage}

Six multiparous Holstein dairy cows in mid to late lactation with SCC less than 250,000 cells/mL were selected from the Cornell Research Farm (Harford, NY) herd. Four of the cows contained rumen fistulas. On average, cows were $4 \pm 0.63 \mathrm{yr}$ old, $178 \pm 22.3$ DIM, had $660 \pm 52.4 \mathrm{~kg}$ of $\mathrm{BW}$, and average milk yield and SCC were $48.0 \pm 2.23 \mathrm{~kg} / \mathrm{d}$ and $24,000 \pm 5,800$ cells/ $\mathrm{mL}$ (all results are means $\pm \mathrm{SD}$ ), respectively.

In a preliminary study, sheep with average BW of $28.7 \mathrm{~kg}$ were fed $6 \mathrm{~g}$ of FRA via oral bolus with no negative effects on DMI or ADG (Soberon et al., 2012a); this represented $159 \%$ of the ingested FRA in the diet. Thus, a dosage of $150 \mathrm{~g}$ for cows $(600 \mathrm{~kg}$ with expected DMI of $24 \mathrm{~kg} / \mathrm{d}$ ) was chosen as a safe dosage of sufficient concentration to detect FRA in the plasma, rumen fluid, milk, and urine.

\section{Experimental Design}

Prior to the sampling period, cows were given 14 $\mathrm{d}$ of adaptation to tiestall location. To allow for individual feed intake measurements, cows were housed in individual tiestalls. Ad libitum access to water and a TMR based on haylage and corn silage (31.1\% NDF containing $5.52 \mathrm{mg}$ of FRA/g) was provided during the study and adaptation period (Table 1). The diet was not different from the diet used for other cattle in the herd at the same stage of lactation. Cows were fed daily at $0830 \mathrm{~h}$. A crossover design was implemented so that each cow alternated weekly between FRA-dosed and control. Fistulated $(\mathrm{n}=4)$ and nonfistulated $(\mathrm{n}=2)$ cows were balanced among treatments. All cows were housed in metabolic tiestalls adjacent to their customary tiestalls during the 3 -d sampling period. At the conclusion of the first sampling period on $\mathrm{d} 3$, cows returned to their tiestall and were milked in the farm dairy parlor for the next $4 \mathrm{~d}$ before commencing the second week of treatment.
Table 1. Chemical composition of the $\mathrm{TMR}^{1}$

\begin{tabular}{lc}
\hline Item & TMR \\
\hline DM, \% & 45.9 \\
CP, \% of DM & 15.9 \\
Soluble protein, \% of CP & 41.9 \\
NDF, \% of DM & 32.0 \\
Roughage NDF, \% of DM & 22.2 \\
Digestible NDF, \% of DM & 16.8 \\
Starch, \% of DM & 26.9 \\
Fat, \% of DM & 3.52 \\
NE, Mcal/kg & 1.65 \\
Sulfur, \% of DM & 0.22 \\
Calcium, \% of DM & 0.84 \\
Phosphorus, \% of DM & 0.43 \\
Magnesium, \% of DM & 0.32 \\
Potassium, \% of DM & 1.04 \\
Copper, mg/kg & 17.6 \\
Iodine, mg/kg & 1.05 \\
Added selenium, mg/kg & 0.30 \\
Zinc, mg/kg & 80.9 \\
Vitamin A, IU/g & 6.22 \\
Vitamin E, IU/kg & 36.2 \\
Monensin, mg/kg & 14.4 \\
\hline
\end{tabular}

${ }^{1}$ Includes $61.4 \%$ corn silage, $15.7 \%$ hay silage, $12.9 \%$ grain concentrate mix, $6.3 \%$ corn meal, and $3.7 \%$ corn distillers grains.

${ }^{2}$ Analysis at Cornell Animal Science Laboratory (Ithaca, NY); values were $31.1 \% \mathrm{NDF}, 16.6 \% \mathrm{ADF}$, and $1.86 \%$ lignin.

On d 1 of each experimental period, an indwelling jugular catheter (Tygon microbore tubing; Norton Performance Plastics, Akron, OH) and urine catheter (Bard Urologic Catheters; Mohawk Medical, Utica, NY) was placed in each cow. On d 2, FRA-dosed cows received a single dosage of $150 \mathrm{~g}$ of pure FRA powder via balling gun and bolus or fistula at $0830 \mathrm{~h}$. Plasma, urine, feces, feed, orts, milk, and rumen fluid were sampled intensively for the next $36 \mathrm{~h}$. Ferulic acid (The Lab Depot Inc., Dawsonville, GA) was encapsulated in size 7 capsules (Torpac Inc., Fairfield, NJ) and orally dosed with a balling gun (Nasco, Fort Atkinson, WI). Study protocol and procedures for this experiment 2008-0183 were approved by the Cornell University Institutional Animal Care and Use Committee.

\section{Sampling}

Prior to the initial FRA administration on d 2 of each experimental period, samples of rumen fluid, blood, urine, milk, and feces were collected to be analyzed for basal levels of FRA concentration. During the sampling periods, feed and feed refusals were weighed and recorded daily; all samples were then stored at $-20^{\circ} \mathrm{C}$ pending subsequent analysis for concentrations of FA, $\mathrm{NDF}, \mathrm{ADF}$, and lignin.

Rumen fluid was collected every $30 \mathrm{~min}$ for the first $2 \mathrm{~h}$ after FRA administration, hourly for the next $3 \mathrm{~h}$, and once more at $12 \mathrm{~h}$ after dosage. Rumen contents 
were sampled from 5 standardized locations in the rumen, strained through cheesecloth, and the rumen fluid was collected and frozen at $-20^{\circ} \mathrm{C}$ until analyzed for FRA concentration.

Blood collection took place every $15 \mathrm{~min}$ for the first $2 \mathrm{~h}$ after FRA administration, every $30 \mathrm{~min}$ for the next $4 \mathrm{~h}$, and hourly thereafter until $12 \mathrm{~h}$ after dosage. Approximately $5 \mathrm{~mL}$ of blood was collected via jugular catheter using a $6-\mathrm{mL}$ syringe preloaded with $100 \mu \mathrm{L}$ of heparinized sterile saline $(40 \mathrm{U} / \mathrm{mL})$ and subsequently centrifuged at $2,500 \times g$ for $20 \mathrm{~min}$ at $4^{\circ} \mathrm{C}$ and. Plasma was frozen at $-20^{\circ} \mathrm{C}$ until assayed for FRA concentration.

Total urine produced in the 30 -h period following FRA administration was collected every $2 \mathrm{~h}$ for the first $12 \mathrm{~h}$, every $4 \mathrm{~h}$ for the subsequent 12 -h period, and every $8 \mathrm{~h}$ until $30 \mathrm{~h}$ had passed after dosage. Urine was collected via 5 gallon polybag (Cornell Dairy Plant, Ithaca, NY), weighed, and an aliquot was frozen at $-20^{\circ} \mathrm{C}$ until assayed for FRA concentration.

Milk was collected via bucket milker (DeLaval Inc., Kansas City, MO) 3 times daily before and during the experimental periods. Total milk for each cow was weighed and recorded. Two representative samples were stored in 3-oz (85-g) polypropylene vials and immediately frozen in liquid $\mathrm{N}$ and stored subsequently at $-80^{\circ} \mathrm{C}$ until assayed for FRA concentration. A third sample was collected and analyzed for milk composition at Dairy One Laboratory (Ithaca, NY).

A subsample of feces was collected every $6 \mathrm{~h}$ for $36 \mathrm{~h}$, weighed, and frozen until assayed for FRA, NDF, ADF, and lignin concentrations.

\section{Analyses}

Feed, rumen fluid, feed refusals, and fecal samples were collected during the experimental periods, weighed, and dried at $60^{\circ} \mathrm{C}$ for $72 \mathrm{~h}$. All were ground through a 1-mm screen using a Wiley mill (Thomas Scientific Inc., Swedesboro, NJ) and $0.25 \mathrm{~g}$ of feed, feed refusals, and fecal samples also were analyzed for NDF, ADF, and ADL (Ankom Technology Corp., Macedon, $\mathrm{NY}$ ). Sodium sulfite and heat-stable $\alpha$-amylase were used; heat and agitation cycles were $80 \mathrm{~min}$.

Feed, orts, rumen fluid, and fecal samples also were analyzed for FRA concentration at Miner Institute (Chazy, NY) according to the procedures as described by Soberon et al. (2012a). Ferulic acid was quantified using modified procedures of Iiyama et al. (1990) and Jung and Shalita-Jones (1990). Total (ester- and etherlinked) FRA was extracted from $100 \mathrm{mg}$ of neutral detergent residue. Identification and quantification of FRA in TMR, orts, rumen fluid, and fecal samples was conducted on an HPLC system (Varian ProStar; Var- ian Inc., Palo Alto, CA) as described in Soberon et al. (2012a).

An adaptation to the methods of Zhao et al. (2003) was used to prepare and analyze plasma and urine samples for FRA concentration, obtained from Soberon et al. (2012a). The FRA standard was 4-hydroxy3-methoxycinnamic acid (99\%) from Sigma-Aldrich (St. Louis, MO). Sample identification was confirmed by comparing retention times and absorption spectra to those of standard materials.

Milk sample preparation methods for FRA analysis were implemented according to methods described in Soberon et al. (2012b) with the addition of a $\mathrm{NaOH}$ digestion to release bound forms of FRA. To prepare milk for the analysis of FRA concentration, raw, whole milk samples were thawed in a water bath without light, and centrifuged at $2,500 \times g$ for $15 \mathrm{~min}$ at $4^{\circ} \mathrm{C}$. The upper fat layer was removed and $4 \mathrm{~mL}$ was pipetted into a $50-\mathrm{mL}$ centrifuge tube (Fisher Scientific, St. Louis, MO). Two milliliters of HPLC-grade hexanes (Fisher Scientific) was added to the milk and the sample was vortexed for 5 min, centrifuged at $2,500 \times g$ for 5 min at $4^{\circ} \mathrm{C}$, and the hexane layer was removed to extract lipids; this was repeated. Samples were digested for $1 \mathrm{~h}$ with $11 \mathrm{~mL}$ of HPLC-grade $2 M$ sodium hydroxide (Fisher Scientific) on a vortexer. Samples were acidified to $\mathrm{pH} 2.0$ with $1.875 \mathrm{~mL}$ of $12 M$ hydrochloric acid (Fisher Scientific). Ethyl acetate extraction was performed 5 times where $6 \mathrm{~mL}$ of HPLC-grade ethyl acetate was added to the acidified, defatted milk; the sample was vortexed for 5 min, centrifuged at $2,500 \times g$ for $5 \mathrm{~min}$ at $4^{\circ} \mathrm{C}$, and the ethyl acetate layer was collected and pooled. The ethyl acetate fraction was evaporated to dryness using a rotary vacuum evaporator in a water bath at $46^{\circ} \mathrm{C}$. The sample was reconstituted in $70 \%$ methanol/water and transferred to an amber HPLC vial (Fisher Scientific), where it was stored at $-40^{\circ} \mathrm{C}$ until analysis.

Identification and quantification of FRA in milk was conducted on a tandem HPLC (Ultimate 3000; Dionex Corp., Sunnyvale, CA) mass spectrometer (4000 Q Trap with TurboIonSpray source; AB Sciex, Foster City, CA) system using a Vydac C18 column $(1 \times 150 \mathrm{~mm}, 5$-um i.d., 300A; The Separations Group Inc., Hesperia, CA). A binary gradient system consisting of solvent A: $0.1 \%$ Optima mass spectrometry-grade formic acid (Fisher Scientific, Pittsburgh, PA) in Milli-Q water (Millipore Corp., Bedford, MA) and solvent B: 0.1\% Optima mass spectrometry-grade formic acid in 95\% Optima mass spectrometry-grade acetonitrile/Milli- $\mathrm{Q}$ water was used in linear gradient mode: the gradient was held at $5 \% \mathrm{~B}$ for 2 min, followed by a linear increase to $40 \% \mathrm{~B}$ over 20 min, an increase to $90 \%$ B in 1 min, held at $90 \%$ B for $5 \mathrm{~min}$, and then decreased to $5 \% \mathrm{~B}$ in $1 \mathrm{~min}$ and held at $5 \% \mathrm{~B}$ for $20 \mathrm{~min}$ to equilibrate prior to the 
next injection. The flow rate was $75 \mu \mathrm{L} / \mathrm{min}$ and the column temperature was maintained at $30^{\circ} \mathrm{C}$. The mass spectrometer was operated in negative ion multiple reaction monitoring- (MRM) information-dependent acquisition (MRM-IDA) mode with settings ion spray voltage $=-4200 \mathrm{~V}$, curtain gas flow $=30$, gas 1 flow $=20$, gas 2 flow $=35$, interface temperature $=280^{\circ} \mathrm{C}$, and collision gas flow $=$ medium. The MRM transition ions for quantification were optimized using standard compounds: 4-hydroxy-3-methoxycinnamic acid (FRA; Acros Organics, Morris Plains, NJ) and a-cyano-4hydroxycinnamic acid (CHCA; Aldrich Chemical Corp., Milwaukee, WI) for use as the internal standard. Peaks for quantification were determined by matching retention times with MRM transition ion pairs, Q1 mass $=193 / \mathrm{Q} 3$ mass $=134$ for FRA and Q1 mass $=188 /$ $\mathrm{Q} 3$ mass $=93$ for $\mathrm{CHCA}$ (where Q1 = quadrupole 1 and Q3 = quadrupole 3), and identity was confirmed by comparing collision-induced dissociation (CID; tandem mass spectrometry, MS/MS) spectra with those obtained from the standard compounds. Ultraviolet absorbance data was also acquired at 214 and $280 \mathrm{~nm}$ but was not useful for quantification or identification purposes. Ten milliliters was injected for quantification and dilutions made as necessary so the analyte signal fell in the linear range of the calibration curve.

\section{Statistical Analysis}

Data were statistically analyzed using a mixed model with repeated measures and period to account for the factorial design. Treatment, the order of treatment for each cow, baseline measure, period, time within period, and their interactions were included in the model as fixed effects; cow was treated as a random variable to account for individual variation among animals and each cow served as her own control to further minimize variation. Terms were removed from the model if not significant. Data are reported as least squares means \pm standard error of the mean; effects were considered significantly different when $P<0.05$. The PROC MIXED procedure of SAS (SAS Institute Inc., Cary, NC) was used for the analyses.

\section{RESULTS AND DISCUSSION}

\section{FRA Distribution in Feed and Feces}

The 150-g dosage of free FRA represented $121 \%$ of the average total FRA ingested via TMR ( $\mathrm{g}$ of FRA/ cow); averaged across both treatments, cows ate an average of $22.7 \mathrm{~kg}$ of DM and the TMR contained 5.52 mg of FRA/g (Table 2). Using multienzyme cocktails, researchers have reported between 65 and $95 \%$ release of FRA from various feedstuffs after incubation (Faulds and Williamson, 1995; Faulds et al., 2002; Yu et al., 2002), so the 150-g dosage exceeded what might be released with the use of feed pretreatments. Also, as only ester-linked FRA is likely to be released, this dosage represents closer to $200 \%$ of the FRA that would be expected to be released. As such, it was sufficient to track the distribution of FRA throughout the body.

In agreement with results of a preliminary study where FRA was dosed to ram lambs (Soberon et al., 2012a), no effect of FRA administration was observed on fecal or orts FRA concentration $(P=0.40$ and 0.06 , respectively); DMI $(P=0.59)$; NDF, ADF, or lignin content of orts $(P=0.46,0.46$, and 0.49 , respectively); or NDF, ADF, or lignin content of feces $(P=0.39$, 0.85 , and 0.72 , respectively; Table 2). Although lignin is often described as indigestible, the use of lignin as a marker for digestion is viewed with some caution due to incomplete lignin recoveries. These incomplete recoveries have been explained in part by apparent digestion due to the formation of soluble lignin-carbohydrate complexes that pass from the rumen and are not recov-

Table 2. Distribution of bound ferulic acid (FRA)

\begin{tabular}{lcccc}
\hline Item & FRA-dosed $^{1}$ & Control & SEM & $P$-value \\
\hline TMR $^{2}$ g of intake & 124.2 & 126.4 & & 0.59 \\
Orts & & & & \\
NDF, \% DM & 29.8 & 28.9 & 1.06 & 0.46 \\
ADF, \% DM & 16.7 & 16.0 & 0.816 & 0.46 \\
Lignin, \% DM & 1.81 & 1.66 & 0.194 & 0.49 \\
FRA, mg/g & 6.06 & 5.62 & 0.150 & 0.06 \\
Feces & 53.6 & 53.0 & 0.680 & 0.39 \\
NDF, \% DM & 29.7 & 29.6 & 0.582 & 0.85 \\
ADF, \% DM & 6.06 & 6.14 & 0.224 & 0.72 \\
Lignin, \% DM & 5.91 & 5.63 & 0.325 & 0.40 \\
FRA, mg/g & & & & \\
\hline
\end{tabular}

${ }^{1}$ Ferulic acid-dosed cows were administered a 150-g dosage of FRA.

${ }^{2}$ The TMR contained $31.1 \% \mathrm{NDF}, 16.6 \% \mathrm{ADF}, 1.86 \%$ lignin, and $5.52 \mathrm{mg}$ of FRA/g; the average DMI was 22.5 $\mathrm{kg} / \mathrm{d}$ for FRA-dosed and $22.9 \mathrm{~kg} / \mathrm{d}$ for control cows. 
ered in fecal residues, the partial destruction of the fecal lignin fraction by reagents used in analyses, as well as physical or chemical differences (or both) between the substances defined as lignin in feed versus feces (Muntifering, 1982). In a study investigating the apparent digestibility of lignin in the digestive tract of sheep, Fahey et al. (1980) attributed the apparent digestibility to the disappearance of phenolic monomers such as $p$ coumaric acid, FRA, and vanillin. They compared the concentration of FRA in the lignin fraction of feed and feces for various roughages. As a result, they expressed support for the idea that the formation of soluble lignin-carbohydrate complexes by rumen microbial action on grasses could account for the apparent digestion of approximately $50 \%$ of the total lignin intake. When comparing the micrograms of FRA per gram of lignin in the TMR versus feces of cows in our study, we observed $66 \%$ disappearance of FRA in the feces. This would suggest that rumen microbial esterases were efficient in releasing some of the feed-derived FRA as described in Fahey et al. (1980). This also may explain some of the high concentrations of FRA in the cows' urine.

\section{FRA Distribution in Rumen Fluid}

Ruminal fluid FRA concentration increased dramatically within $30 \mathrm{~min}$ of the dosage and decreased steadily thereafter, returning to basal levels between 3 and $4 \mathrm{~h}$ after dosage (Figure 1). Therefore, by $4 \mathrm{~h}$ after dosage, the 150-g FRA dosage had yielded to one of the following fates: absorption through the rumen wall into the blood, degradation in the rumen, or it had washed out of the rumen with liquid flow to be absorbed or transformed at another point in the digestive tract.

Certain cellulolytic bacteria are able to perform the preliminary degradative steps in the breakdown of FRA but the complete breakdown would require a ruminal retention time that is not physiologically feasible as well as larger populations of these bacteria (Besle et al., 1995). The most likely degradation products of FRA are phenyl-3-propionic and benzoic and cinnamic acids (Chesson et al., 1982; Cremin et al., 1995) and of these, the most likely to appear in the blood are benzoic and phenylpropionic acids (Cremin et al., 1995).

\section{FRA Distribution in Plasma and Urine}

Absorption of FRA from the rumen began almost immediately, with the peak plasma FRA concentration at the first sample after dosage, 15 min after FRA administration (Figure 2). The concentration of FRA in plasma of the FRA-dosed cows returned to basal concentrations by $5.5 \mathrm{~h}$ after dosage (Figure 2). Similarly, within $5 \mathrm{~h}$ of FRA dosage in ram lambs orally

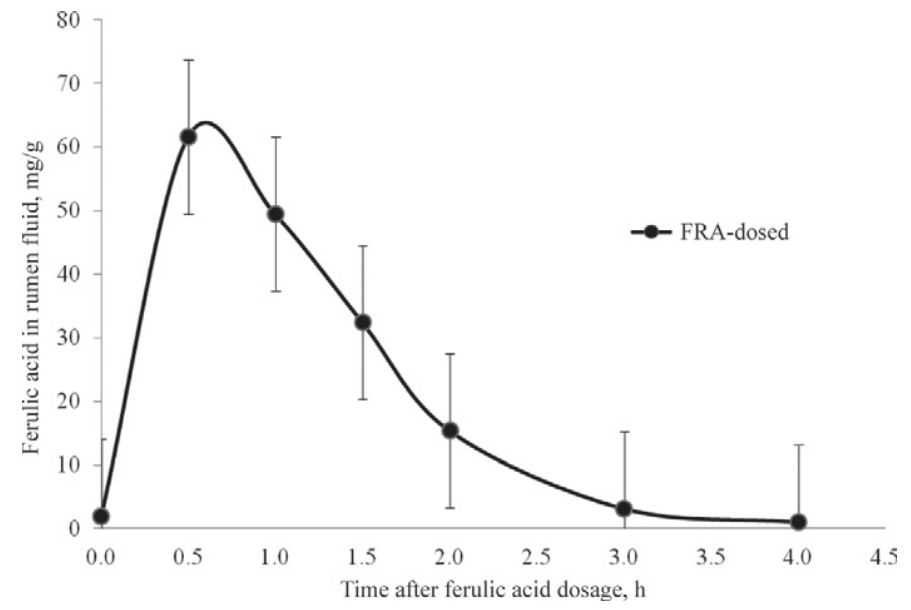

Figure 1. Ruminal fluid ferulic acid (FRA) concentration over time for fistulated cows; FRA-dosed cows $(\mathrm{n}=4)$ received a dosage of $150 \mathrm{~g}$ of FRA immediately following the 0-min rumen fluid sample.

administered 3, 6, or $9 \mathrm{~g}$ of FRA, FRA was no longer present in the blood (Soberon et al., 2012a) and for rats, orally administered free FRA had almost completely disappeared from blood plasma by 30 min after dosage (Zhao et al., 2003).

Following its absorption in the blood, FRA was excreted in the urine at levels significantly greater than basal levels by 45 min after dosage, peaking at $2.75 \mathrm{~h}$ after dosage (Figure 3). This compares with a peak time of maximal urinary excretion in humans fed FRA from tomatoes at $7 \mathrm{~h}$ after ingestion (Bourne and RiceEvans, 1998). The difference may be explained by the use of urinary catheters in the cows, which allowed the collection of urine at almost the same time that it was produced, whereas in the human study, individuals were allowed to urinate at their discretion, allowing for variation in the time of collection. By $14 \mathrm{~h}$ after dosage,

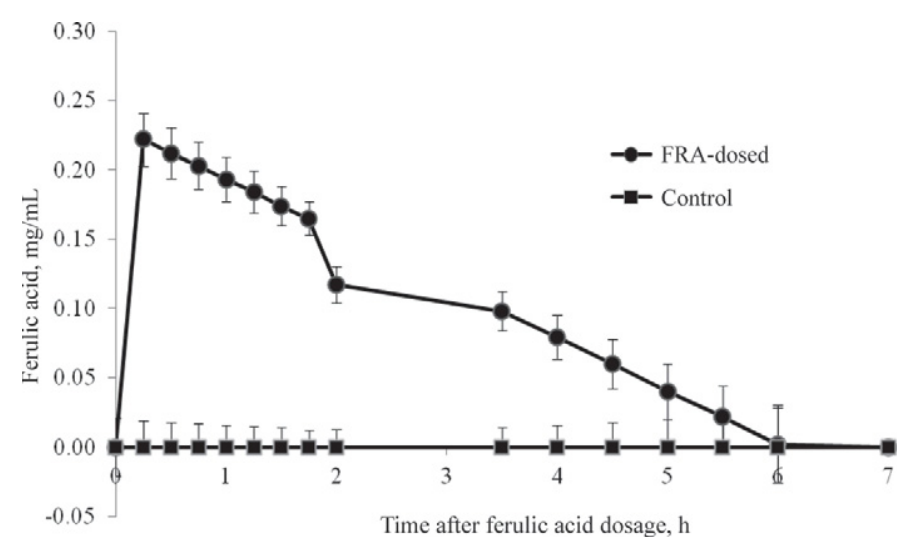

Figure 2. Plasma ferulic acid (FRA) concentration over time for control versus FRA-dosed cows; FRA-dosed cows $(\mathrm{n}=6)$ received a dosage of $150 \mathrm{~g}$ of FRA immediately following the 0-min blood sample. 


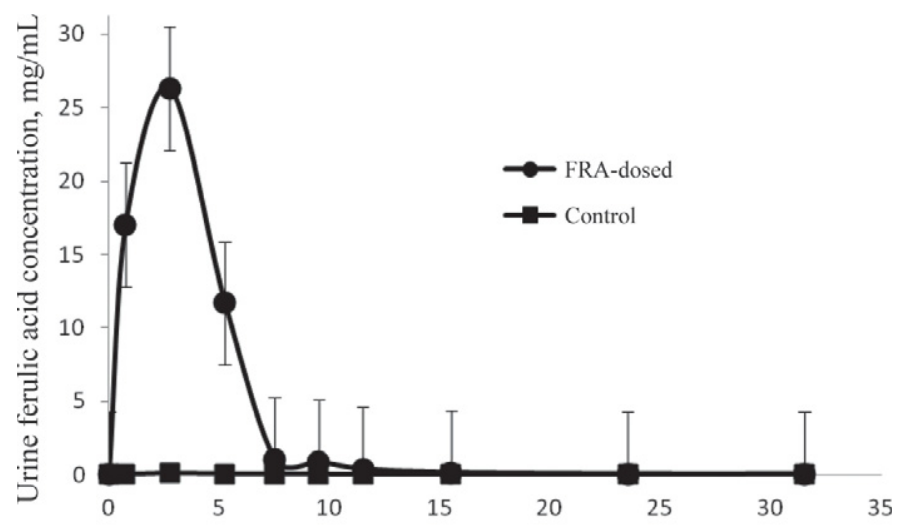

Time after ferulic acid dosage, $\mathrm{h}$

Figure 3. Urine ferulic acid (FRA) concentration over time for control versus FRA-dosed cows; FRA-dosed cows $(\mathrm{n}=6)$ received a dosage of $150 \mathrm{~g}$ of FRA immediately following the 0 -h urine sample.

both urine and milk FRA concentrations had returned to basal levels (Figure 3, 4).

In a study where humans were fed a polyphenol-rich diet, and plasma and urine were sampled frequently, great individual variation in absorption and metabolism of dietary polyphenols was observed (Rechner et al., 2002). Similarly, although the same general trend of increased FRA in bovine plasma and urine was observed after dosage, followed by a gradual decrease in FRA concentration, individual variation in each cow was also observed. Part of the variation could be explained in the statistical analysis by the effect of individual basal FRA levels before FRA administration.

\section{FRA Distribution in Milk}

No effect of FRA administration was observed on milk yield $(P=0.50)$, milk fat yield $(P=0.46)$, milk protein yield $(P=0.96)$, or SCC $(P=0.50$; Table 3$)$. Similar to urine FRA concentration, basal levels were achieved by $14 \mathrm{~h}$ after dosage (Figure 4). Although we can know with confidence that the peak excretion of FRA in milk occurred within $6 \mathrm{~h}$ of FRA dosage, it is difficult to accurately gauge the exact time of peak

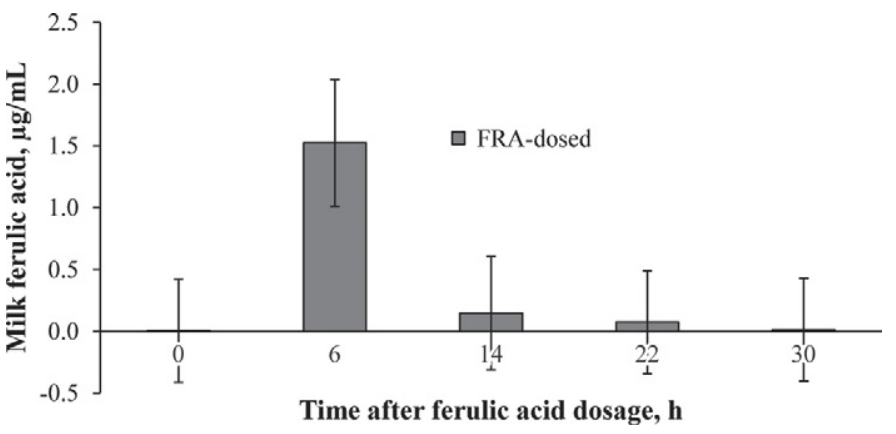

Figure 4. Average ferulic acid (FRA) concentration $(\mu \mathrm{g} / \mathrm{mL})$ in milk at each milking before $(0 \mathrm{~h})$ and after a dosage of $150 \mathrm{~g}$ of FRA.

FRA excretion because milk was pooled in the udder cistern continuously until its collection, which was coordinated with the $3 \times$ milking schedule. Milkings took place at 8-h intervals, beginning $6 \mathrm{~h}$ after dosage.

The average basal concentration of FRA in milk was $0.004 \mu \mathrm{g} / \mathrm{mL}$, which is equivalent to $4.1 \mu \mathrm{g} / \mathrm{L}$. Besle et al. (2010) observed concentrations of FRA in milk of $3.9 \mu \mathrm{g} / \mathrm{L}$ in cows fed ryegrass hay, $0.9 \mu \mathrm{g} / \mathrm{L}$ in cows fed grassland hay, and $14.7 \mu \mathrm{g} / \mathrm{L}$ in cows fed grassland pasture. The authors stated that this was the first observation to their knowledge where FRA was identified in milk (Besle et al., 2010). In cows fed maize silage, such as in the present study, a certain amount of free FRA is expected from the ensiling process in addition to that released by microbial esterases in the rumen (Ostrander et al., 1999). The origin of FRA in the milk of control cows can be attributed to this ruminal degradation of soluble polyphenols and cell wall aromatics, which are then absorbed through the rumen and intestinal mucosa, and are subsequently excreted in urine or milk (Scheline, 1991).

Whereas some of the ingested FRA escaped the rumen to be transferred into milk, as described previously, it is likely that some of the FRA in the rumen was transformed by rumen bacteria into phenyl-3-propionic, phenylacetic, cinnamic, or benzoic acids (Chesson et al., 1982; Cremin et al., 1995). These precursors can result in increased hippuric acid concentrations in milk, as described in Besle et al. (2010), who observed el-

Table 3. Effect of ferulic acid (FRA) dosage on milk composition and yield ${ }^{1}$

\begin{tabular}{|c|c|c|c|c|}
\hline Item & FRA-dosed $^{2}$ & Control & SEM & $P$-value \\
\hline Fat, $\%$ & 3.70 & 3.71 & 0.216 & 0.96 \\
\hline Fat yield, g & 421 & 441 & 26.2 & 0.46 \\
\hline True protein, $\%$ & 3.00 & 2.87 & 0.062 & 0.05 \\
\hline True protein yield, g & 354 & 355 & 17.5 & 0.96 \\
\hline $\mathrm{SCC}, \times 1,000$ cells $/ \mathrm{mL}$ & 79.4 & 64.6 & 21.2 & 0.50 \\
\hline Yield, kg & 12.2 & 12.6 & 0.631 & 0.50 \\
\hline
\end{tabular}

${ }^{1}$ All values represent daily averages of 3 milkings per day.

${ }^{2}$ Ferulic acid-dosed cows were administered a 150-g dosage of FRA. 
evated hippuric acid in milk of dairy cows as a result of consuming diets rich in polyphenols. The potential effect of increased hippuric acid in milk designated for cheese production is important to consider, given that hippuric acid has been shown to be a precursor in the synthesis of benzoic acid by lactic acid bacteria in milk (Sieber et al., 1995). Benzoic acid can affect cheese flavor and act as a natural preservative in cheeses.

\section{Effect of FRA in Milk}

Ferulic acid may affect the functionality of milk in terms of antioxidant, cholesterol-lowering, antimicrobial, antiinflammatory, antithrombosis, and anticancer activities in addition to acting as a potential chemopreventive agent against coronary heart disease $(\mathrm{Ou}$ and Kwok, 2004) and Alzheimer's disease (Yan et al., 2001). An average of $7.28 \mathrm{mg}$ of FRA was recovered in the milk within $30 \mathrm{~h}$ of dosage for FRA-dosed cows compared with $0.10 \mathrm{mg}$ for control cows. The peak concentration of FA in milk after dosage was $1,500 \mu \mathrm{g} / \mathrm{L}$ and the basal concentration before FRA dosage was 4.1 $\mu \mathrm{g} / \mathrm{L}$ (Figure 4).

Increased antioxidant activity is the primary health benefit expected from milk with increased FRA concentrations. The antioxidant activity of FRA comprises high scavenging activity for hydrogen peroxide, superoxide, hydroxyl radicals, and nitrogen dioxide free radicals as well as its inhibition of enzymes that produce free radicals, and ability to increase the activity of enzymes that scavenge free radicals (Ou and Kwok, 2004). The antioxidant activity of natural bovine milk from cows fed the same maize silage-based TMR as the cows in the current study, was measured at $52.7 \mu \mathrm{mol}$ of vitamin $\mathrm{C}$ equivalents per milliliter of milk (Soberon et al., 2012b). In a study that investigated the contribution of different beverages to total antioxidant intake in the Spanish diet where the most-consumed beverage was milk (mean daily intake of $317.8 \mathrm{~mL}$ ), coffee accounted for the highest percentage of daily antioxidant intake at $66 \%$, followed by red wine $(16 \%)$, with milk accounting for $4 \%$ of daily antioxidant intake (Pulido et al., 2003). A similar study in Norway comparing total dietary antioxidant intake of 61 adults also found coffee (mean daily intake of $480 \mathrm{~mL}$ ) was the major source of antioxidant intake $(66 \%)$, followed by fruits, tea, cereals, wine, and vegetables, which contributed 26, 25, 13 , 10 , and $6 \%$ of total dietary antioxidants, respectively (Svilaas et al., 2004). These studies indicate that room for improvement exists for the antioxidant activity of milk.

At $200 \mu M$ concentration in an ethanol-buffer solution of linoleic acid, FRA was the most effective hydroxycinnamic acid tested, with an antioxidant activity similar to that of $\alpha$-tocopherol (Kikuzaki et al., 2002). In addition, cows in our study received a $0.25 \mathrm{-g} / \mathrm{kg}$ dosage of FRA; rats fed an FRA dosage of $0.1 \mathrm{~g} / \mathrm{kg}$ had significantly increased activities of detoxifying enzymes such as glutathione $S$-transferase and quinine reductase (Kawabata et al., 2000).

Due to its antimicrobial activity toward a wide spectrum of gram-positive and gram-negative bacteria (Ou and Kwok, 2004), FRA also has potential microbiological effects in milk. Not only do O'Connell and Fox (2001) detail the usefulness of phenolic compounds for increasing shelf life and stability of milk, but they report that FRA specifically inhibited the growth of pathogenic bacteria with little effect on lactic acid bacteria in milk.

Increased FRA and its degradation products may also have a potential effect on sensory properties of milk and cheese. Even at the peak concentration of FRA in milk observed in this study $(1,500 \mu \mathrm{g} / \mathrm{L})$, which is $121 \%$ of what was present in the diet, FRA is far below the detection threshold measured by Work and Camire (1996) of 62,000 $\mu \mathrm{g}$ of FRA/L of deionized water. However, an indirect flavor effect of increased FRA could result from the direct decarboxylation of FRA into 4-vinylguaiacol, which has been observed in the gut of monogastrics and under anaerobic conditions (Besle et al., 1995). 4-Vinylguaiacol produced from degraded free FRA during storage is responsible for detrimental off-flavors in citrus juices (Naim et al., 1988; Fallico et al., 1996). In beer, the same FRA degradation product is considered an essential flavor contributor inherent to the beer production process in beers made with wheat or wheat malt (Coghe et al., 2004; Vanbeneden et al., 2007). Further research is required to investigate the presence of 4-vinylguaiacol in milk with increased FRA concentration as well as its potential sensory effect in fermented milk products.

\section{CONCLUSIONS}

The administration of FRA did not have any negative effect on cow performance. As expected, FRA concentration increased dramatically upon FRA dosage and decreased over time until returning to basal levels in the milk, rumen fluid, plasma, and urine. The low recovery of FRA in milk at $0.02 \%$ of the administered dosage is an indication of other routes of FRA transformation. Regardless, from this study, it is observed that orally ingested FRA can be transferred into milk and that the physiological transfer of FRA occurs from rumen to milk within $6.5 \mathrm{~h}$ or the first milking after dosage. Future research will be required to elucidate whether the increased FRA concentration in milk is bioavailable and bioactive, and to evaluate the complete sensory 
and microbiological effects of increased FRA and FRA degradation products in milk.

\section{ACKNOWLEDGMENTS}

The authors thank the Department of Animal Science at Cornell University (Ithaca, NY) for financial and academic support as well as Kurt Cotanch (Miner Institute, Chazy, NY), Robert Fievisohn (Miner Institute), and Robert Sherwood (Cornell Proteomics and Mass Spectrometry Facility) for analytical work; Richard Austic, Bruce Berggren-Thomas, Thomas Overton, and Fernando Soberon for assistance with the project; and Francoise Vermeylen (Cornell Statistical Consulting Unit) for her consultation in statistics.

\section{REFERENCES}

Adam, A., V. Crespy, M. A. Levrat-Verny, F. Leenhardt, M. Leuillet, C. Demigné, and C. Rémésy. 2002. The bioavailability of ferulic acid is governed primarily by the food matrix rather than its metabolism in intestine and liver in rats. J. Nutr. 132:1962-1968.

Besle, J.-M., J.-P. Jouany, and A. Cornu. 1995. Transformations of structural phenylpropanoids during cell wall digestion. FEMS Microbiol. Rev. 16:33-52.

Besle, J. M., D. Viala, B. Martin, P. Pradel, B. Meunier, J. L. Berdagué, D. Fraisse, J. L. Lamaison, and J. B. Coulon. 2010. Ultraviolet-absorbing compounds in milk are related to forage polyphenols. J. Dairy Sci. 93:2846-2856.

Bourne, L. C., and C. Rice-Evans. 1998. Bioavailability of ferulic acid Biochem. Biophys. Res. Commun. 253:222-227.

Chesson, A., C. S. Stewart, and R. J. Wallace. 1982. Influence of plant phenolic acids on growth and cellulolytic activity of rumen bacteria. Appl. Environ. Microbiol. 44:597-603.

Coghe, S., K. Benoot, F. Delvaux, B. Vanderhaegen, and F. R. Delvaux. 2004. Ferulic acid release and 4-vinylguaiacol formation during brewing and fermentation: Indications for feruloyl esterase activity in Saccharomyces cerevisiae. J. Agric. Food Chem. 52:602-608.

Cremin, J. D. Jr., K. R. McLeod, D. L. Harmon, A. L. Goetsch, L. D. Bourquin, and G. C. Fahey Jr.. 1995. Portal and hepatic fluxes in sheep and concentrations in cattle ruminal fluid of 3-(4-hydroxyphenyl)propionic, benzoic, 3-phenylpropionic, and trans-cinnamic acids. J. Anim. Sci. 73:1766-1775.

Fahey, G. C. Jr., S. Y. Al-Haydari, F. C. Hinds, and D. E. Short. 1980 Phenolic compounds in roughages and their fate in the digestive system of sheep. J. Anim. Sci. 50:1165-1172.

Fallico, B., M. C. Lanza, E. Maccarone, C. N. Asmundo, and P. Rapisarda. 1996. Role of hydroxycinnamic acids and vinylphenols in the flavor alteration of blood orange juices. J. Agric. Food Chem. 44:2654-2657.

Faulds, C. B., A. I. Sancho, and B. Bartolomé. 2002. Mono- and dimeric ferulic acid release from brewer's spent grain by fungal feruloyl esterases. Appl. Microbiol. Biotechnol. 60:489-494.

Faulds, C. B., and G. Williamson. 1995. Release of ferulic acid from wheat bran by a ferulic acid esterase (FAE-III) from Aspergillus niger. Appl. Microbiol. Biotechnol. 43:1082-1087.

Iiyama, K., T. B. T. Lam, and B. A. Stone. 1990. Phenolic acid bridges between polysaccharides and lignin in wheat internodes. Phytochemistry 29:733-737.

Jung, H. G., and M. S. Allen. 1995. Characteristics of plant cell walls affecting intake and digestibility of forages by ruminants. J. Anim. Sci. 73:2774-2790
Jung, H. J. G., and S. C. Shalita-Jones. 1990. Variation in the extractability of esterified p-coumaric and ferulic acids from forage cell walls . J. Agric. Food Chem. 38:397-402.

Kawabata, K., T. Yamamoto, A. Hara, M. Shimizu, Y. Yamada, K. Matsunaga, T. Tanaka, and H. Mori. 2000. Modifying effects of ferulic acid on azoxymethane-induced colon carcinogenesis in F344 rats. Cancer Lett. 157:15-21.

Kikuzaki, H., M. Hisamoto, K. Hirose, K. Akiyama, and H. Taniguchi. 2002. Antioxidant properties of ferulic acid and its related compounds. J. Agric. Food Chem. 50:2161-2168.

Mathew, S., and T. E. Abraham. 2004. Ferulic acid: An antioxidant found naturally in plant cell walls and feruloyl esterases involved in its release and their applications. Crit. Rev. Biotechnol. 24:59-83.

Muntifering, R. B. 1982. Evaluation of various lignin assays for determining ruminal digestion of roughages by lambs. J. Anim. Sci $55: 432-438$.

Naim, M., B. J. Striem, J. Kanner, and H. Peleg. 1988. Potential of ferulic acid as a pre-cursor to off-flavors in stored orange juice. J. Food Sci. 53:500-503.

O'Connell, J. E., and P. F. Fox. 2001. Significance and applications of phenolic compounds in the production and quality of milk and dairy products: A review. Int. Dairy J. 11:103-120.

Ostrander, B., M. P. Maillot, S. Toillon, Y. Barrière, M. Pollacsek, and J. M. Besle. 1999. Cell wall phenolics and digestibility of normal and brown midrib maizes in different stem sections and across maturity stages. J. Sci. Food Agric. 79:414-415.

Ou, S., and K.-C. Kwok. 2004. Ferulic acid: Pharmaceutical functions, preparation and applications in foods. J. Sci. Food Agric. 84:1261-1269.

Pulido, R., M. Hernández-García, and F. Saura-Calixto. 2003. Contribution of beverages to the intake of lipophilic and hydrophilic antioxidants in the Spanish diet. Eur. J. Clin. Nutr. 57:1275-1282.

Rechner, A. R., G. Kuhnle, P. Bremner, G. P. Hubbard, K. P. Moore, and C. A. Rice-Evans. 2002. The metabolic fate of dietary polyphenols in humans. Free Radic. Biol. Med. 33:220-235.

Scheline, R. R. 1991. Metabolism of oxygen heterocyclic compounds Flavonoids. Pages 267-290 in CRC Handbook of Mammalian Metabolism of Plant Compounds. CRC Press, Boca Raton, FL.

Sieber, R., U. Bütikofer, and J. O. Bosset. 1995. Benzoic acid as a natural compound in cultured dairy products and cheese. Int. Dairy J. 5:227-246.

Soberon, M. A., D. J. R. Cherney, and J. H. Cherney. 2012a. Free ferulic acid uptake in ram lambs. J. Anim. Sci. 90:1885-1891.

Soberon, M. A., R. H. Liu, and D. J. R. Cherney. 2012b. Short communication: Antioxidant activity of calf milk replacers. J. Dairy Sci. 95:2703-2706

Srinivasan, M., A. R. Sudheer, and V. P. Menon. 2007. Ferulic acid: Therapeutic potential through its antioxidant property. J. Clin. Biochem. Nutr. 40:92-100.

Svilaas, A., A. K. Sakhi, L. F. Andersen, T. Svilaas, E. C. Strom, D. R. Jacobs Jr., L. Ose, and R. Blomhoff. 2004. Intakes of antioxidants in coffee, wine and vegetables are correlated with plasma carotenoids in humans. J. Nutr. 134:562-567.

Vanbeneden, N., F. Gils, F. Delvaux, and F. R. Delvaux. 2007. Variability in the release of free and bound hydroxycinnamic acids from diverse malted barley (Hordeum vulgare L.) cultivars during wort production. J. Agric. Food Chem. 55:11002-11010.

Work, T. M., and M. E. Camire. 1996. Phenolic acid detection thresholds in processed potatoes. Food Qual. Prefer. 7:271-274.

Yan, J.-J., J.-Y. Cho, H.-S. Kim, K.-L. Kim, J.-S. Jung, S.-O. Huh, H.W. Suh, Y.-H. Kim, J.-J. Yan, and D.-K. Song. 2001. Protection against $\beta$-amyloid peptide toxicity in vivo with long-term administration of ferulic acid. Brit. J. Pharm. 133:89-96.

Yu, P., D. D. Maenz, J. J. McKinnon, V. J. Racz, and D. A. Christensen. 2002. Release of ferulic acid from oat hulls by Aspergillus ferulic acid esterase and Trichoderma xylanase. J. Agric. Food Chem. 50:1625-1630.

Zhao, Z., Y. Egashira, and H. Sanada. 2003. Ferulic acid sugar esters are recovered in rat plasma and urine mainly as the sulfoglucuronide of ferulic acid. J. Nutr. 133:1355-1361. 